\title{
Stage IVA Major Salivary Gland Cancer AJCC v8
}

National Cancer Institute

\section{Source}

National Cancer Institute. Stage IVA Major Salivary Gland Cancer A/CC v8. NCI Thesaurus. Code C132788.

Stage IVA includes: (T4a, N0, M0); (T4a, N1, M0); (T0, N2, M0); (T1, N2, M0); (T2, N2, M0); (T3, N2, M0); (T4a, N2, M0). T4a: Moderately advanced disease. Tumor invades skin, mandible, ear canal, and/or facial nerve. T0: No evidence of primary tumor. T1: Tumor measuring $2 \mathrm{~cm}$ or less in greatest dimension without extraparenchymal extension. T2: Tumor measuring more than $2 \mathrm{~cm}$, but not more than $4 \mathrm{~cm}$ in greatest dimension without extraparenchymal extension. T3: Tumor measuring more than $4 \mathrm{~cm}$ in greatest dimension, and/or tumor having extraparenchymal extension. N0: No regional lymph node metastasis. N1: Metastasis in a single ipsilateral lymph node, $3 \mathrm{~cm}$ or less in greatest dimension. N2: Metastasis in a single ipsilateral lymph node, $3 \mathrm{~cm}$ or less in greatest dimension and $\mathrm{ENE}(+)$; or more than $3 \mathrm{~cm}$ but not more than $6 \mathrm{~cm}$ in greatest dimension and ENE(-); or metastases in multiple ipsilateral lymph nodes, none more than $6 \mathrm{~cm}$ in greatest dimension and ENE(-), or in bilateral or contralateral lymph nodes, none more than $6 \mathrm{~cm}$ in greatest dimension and ENE(-). M0: No distant metastasis. (AJCC 8th ed.) 